\title{
Pd-Au Alaşımında Au Atomunun Konsantrasyonunun Polyhedron Topakları Oluşumu Üzerine Etkisinin Moleküler Dinamik Yöntemle İncelenmesi
}

\author{
Fatih Ahmet ÇELIK* \\ Bitlis Eren Üniversitesi, Fen-Edebiyat Fakültesi, Fizik Bölümü, Bitlis \\ (ORCID: 0000-0001-7860-5550)
}

\begin{abstract}
Öz
$\mathrm{Bu}$ çalışmada, altının $(\mathrm{Au})$ farklı konsantrasyon oranları için Pd-Au düzenli alaşım sistemlerinin amorf fazda meydana gelen polyhedron türü topakların yapısal özellikleri Moleküler Dinamik (MD) benzetim yöntemi ile belirlendi. Atomlar arasındaki etkileşmeleri belirlemek için çok cisim etkileşmeleri temeline dayanan Gömülmüş Atom Metodu'nun Sutton-Chen (SC) potansiyel fonksiyonu kullanıldı. Sistemlerin farklı Au konsantrasyonu için amorf fazda meydana gelen polyhedron türü topaklar Honeycutt-Andersen (HA) yöntemi ile belirlenen bağlı çiftler ile elde edildi. Sonuç olarak, amorf fazda $\mathrm{Pd}_{10} \mathrm{Au}_{90}$ yapısının ideal icosahedral (icos) türü polyhedron topaklarının oluşumu bakımından en uygun yapı olduğu sonucuna varılmıştır.
\end{abstract}

Anahtar kelimeler: Moleküler Dinamik, Polyhedron topaklanma, Bağlı çiftler, Gömülmüş Atom Metodu.

\section{Investigation of Concentration Effect of Au atoms on Polyhedron Clusters formation at Pd-Si alloy with Molecular Dynamics Method}

\begin{abstract}
In this study, the structural properties of polyhedron clusters which formed at amorphous phase of $\mathrm{Pd}-\mathrm{Au}$ alloy systems was determined by Molecular Dynamics (MD) for different Au concentrations. The Sutton-Chen (SC) potential function version of Embedded Atom Method based on many-body interactions was used to determine interatomic interactions. The polyhedron clusters which formed at amorphous phase was obtained with bonded pairs obtained by Honeycutt-Andersen (HA) method for different $\mathrm{Au}$ concentrations. It was concluded that $\mathrm{Pd}_{10} \mathrm{Au}_{90}$ structure is the most suitable structure for the formation of polyhedron clusters of perfect icosahedral (icos) type at amorphous phase.
\end{abstract}

Keywords: Molecular Dynamics, Polyhedron clusters, Bonded pairs, Embedded Atom Method.

\section{Giriş}

Günümüzde önemli fiziksel özelliklerinden dolayı paladyum (Pd) metalik malzemesi çok çeşitli teknolojik uygulamalarda oldukça sık kullanılmaktadır [1-7]. Pd elementinin yanı sıra, altının ( $\mathrm{Au}$ ) elektriksel ve mekanik özellikleri bakımından çok daha farklı kullanım alanları mevcut olmakla beraber bu kullanım alanları sürekli artmaktadır [8]. Özellikle; basınç, 1sıtma/soğutma hızı ve alaşımların konsantrasyon oranı gibi bazı dış şartların malzemelerin faz geçişi süreci üzerine etkileri son zamanlarda yapılan çalışmalarda görülmektedir [8]. Bununla birlikte, Pd elementine Au eklenmesiyle oluşan ikili alaşımda hızlı soğutma sürecinde meydana gelen amorf fazın oluşum mekanizması hakkında bilgiler oldukça kısıtlıdır $[9,10]$.

$\mathrm{Bu}$ bağlamda, özellikle amorf fazda nano-boyutta meydana gelen atomik topaklanmaların mevcut fazın fiziksel ve yapısal özellikleri hakkında bilgiler vermesi oldukça önemlidir [11]. Tüm bu olumlu özelliklerine rağmen, paladyum içeren alaşımlarda yapılan deneysel çalışmaların yetersiz olduğu görülmektedir. Bunun en önemli sebeplerinden biri, bu metalin oldukça pahalı malzeme olması ve

*Sorumlu yazar:facelik@beu.edu.tr

Geliş Tarihi: 17.09.2020, Kabul Tarihi: 11.01.2021 
doğada nadir bulunmasıdır [5-8]. Son zamanlarda bilgisayar hesaplamalı yöntemler bu tür malzemelerin birçok özelliklerinin açığa çıkması bakımından oldukça sık kullanılan yöntemler olmakla beraber, moleküler dinamik (MD) benzetim (simülasyon) metotları malzemeleri bilgisayar ortamında modelleyerek atomik ölçekte yapısal ve termodinamik gibi birçok fiziksel özelliklerinin belirlenmesi amacıyla kullanılmaktadırlar $[11,12]$.

\section{Materyal ve Metot}

\subsection{Benzetim Yöntemi}

Benzetim yöntemi, deneysel olarak incelenmesi zor olan bazı deneysel ölçümlerin sayısal hesaplama yöntemleri ile elde edilmesini ve modellenen birçok fiziksel özellikleri hakkında bilgiler sağlar [13]. Moleküler Dinamik (MD) yöntemi hesaplama hücresi içine yerleştirilen atomların birbirleri üzerindeki kuvvetleri hesaplayarak faz uzayında dengelenmesi ve daha sonra sistemin algoritma olarak hareket denklemleri çözmek üzerine kurulmuştur [13]. Parrinello ve Rahman (PR) tarafindan geliştirilen benzetim yönteminde hesaplama hücresinin kenar vektörleri zamana bağımlı olan üç vektörle temsil edilir [14].

\subsection{Gömülmüş Atom Metodu (GAM )}

GAM metodunda atomlararası etkileşimler ile meydana gelen sistemin toplam enerji,

$$
E_{\text {top }}=\frac{1}{2} \sum_{\substack{i, j \\ i \neq j}} \phi_{i j}\left(R_{i j}\right)+\sum_{i} F_{i}\left[\rho_{i}\right]
$$

ile gösterilir. İlk terim iki cisim arasında itici etkileşimleri temsil ederken ikinci terim ise çekici etkileşimleri içeren yük yoğunluğuna bağl1 gömme enerjisi fonksiyonudur $[15,16]$.

$$
\rho_{i}=\sum_{j=(\neq i)}^{N} \rho_{j}\left(r_{i j}\right)
$$

\subsection{Honeycutt-Andeersen (HA) metodu}

Amorf veya kristal fazlarda meydana gelen atomik topakların yapısal özelliklerini belirlemek amacıyla Honeycutt ve Andersen (HA) [17] tarafindan öne sürülen çok yararlı bir yöntem mevcuttur. Bir atomik topağın amorf yapıyı temsil eden bir topak mı yoksa kristal yapıyı temsil eden bir topak mı olduğu o topağ 1 meydana getiren az sayıda atomun meydana getirdiği bağlı çiftlere bakılır. Burada atomik topaktaki bağlı çiftlerin geometrisi dört temel indis ile tanımlanır. Mesela; 1551 bağlı çifti ideal bir icosahedral topağın temel bağlı çifti olup; 1 indisi bir atom çifti arasında bağlanma olduğunu gösterir, 5 indisi bu atom çifti tarafından paylaşılan yakın-komşu sayısıdır, diğer 5 indisi yakın komşular arasında paylaşılan bağ sayısını ifade etmektedir. Son indis ise, atomik topaklar arasında geometrik farklı1ığı belirtir. Yukarıda belirtilen durumlara göre bazı bağ çiftlerinin şematik görünümü Şekil 1'de gösterilmiştir [17].

HA analizine göre, 1551 bağlı çifti ideal icosahedral (ICOS) topağının temel bağlı çiftidir. 1421 bağlı çifti yüzey merkezli kübik (FCC), 1422 bağ çifti Hegzagonal (HCP) ve 1661, 1441 bağlı çiftleri ise cisim merkezli kübik (BCC) yapısını temsil eder [17]. 


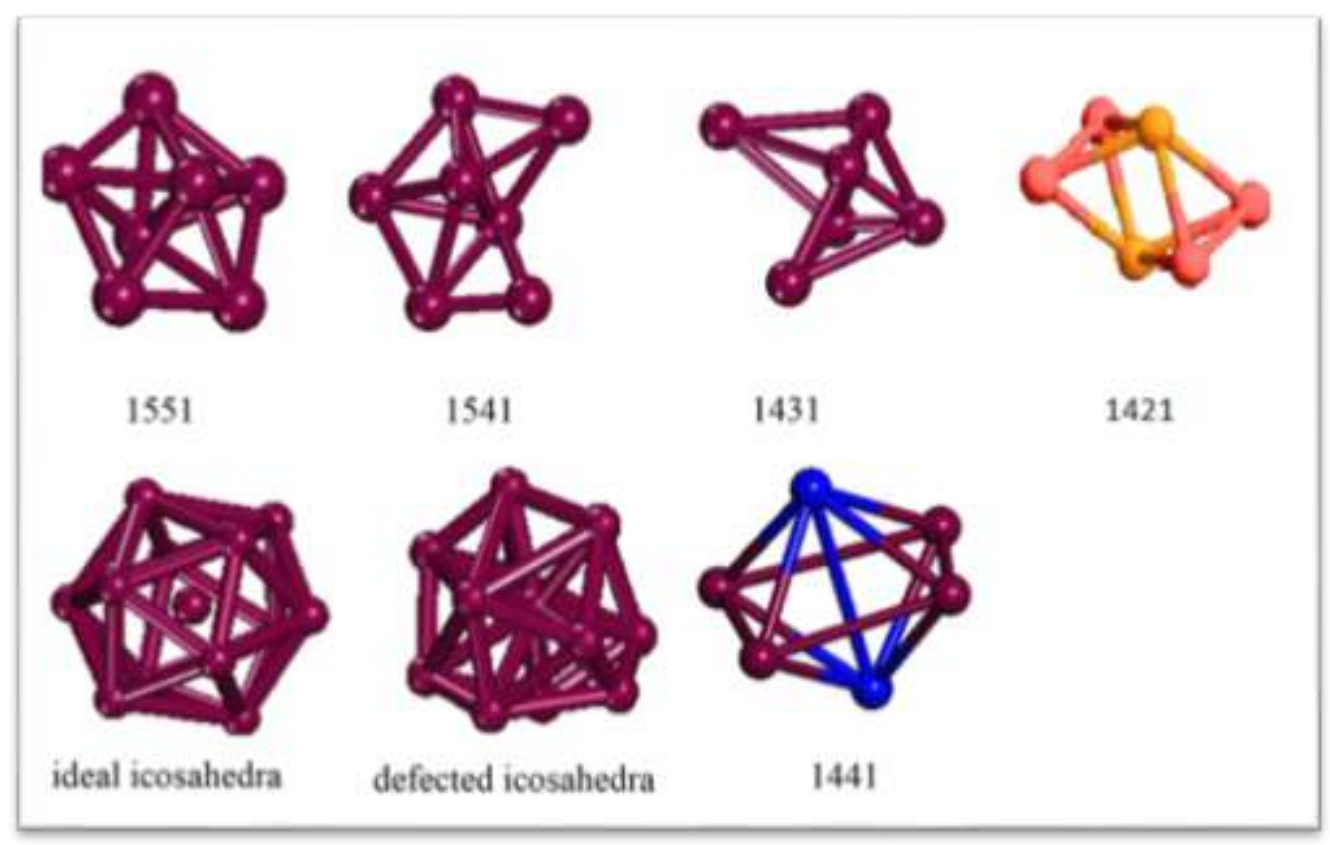

Şekil 1. Farklı türlerdeki bağlı çiftlerin gösterimi

\subsection{Cluster-type index metod (CTIM) metodu}

HA analizine göre belirlenen farklı yapıdaki bağlı çiftlerin oluşturduğu kombinasyonlar ile sistem içinde meydana gelen polyhedronları belirlemek mümkündür. Cluster-type index metod (CTIM) metoduna göre dört integer sayı ile farklı tür polyhedral yapılar incelenebilir [18]. Örnek olarak; (12 0 12 0 ) olarak nitelendirilen ideal icosadral polyhdron yapısında ilk sayı merkez atomun sahip olduğu komşu atom sayısını (12), ikinci sayı 1441 türü bağlı çiftlerin sayısı, üçüncü sayı 1551 türü bağlı çiftlerin sayısını, dördüncü sayı ise 1661 türü bağlı çiftlerin sayısını göstermektedir. (13 1102 2) polyhedronu bir kusurlu (defekte) olmuş icosahedral yapıyı temsil etmektedir. Önemli olarak nitelendirilen polyhedron türlerinden biri Frank-Kasper (FK) polyhedronu (14 0 12 2), Bernal poyhedronu ise (10 28 0) ile temsil edilir. Şekil 2'de sistem içinde meydana gelen farklı türde polyhedronların üç boyutta bir görünümü verilmektedir $[19,20]$.

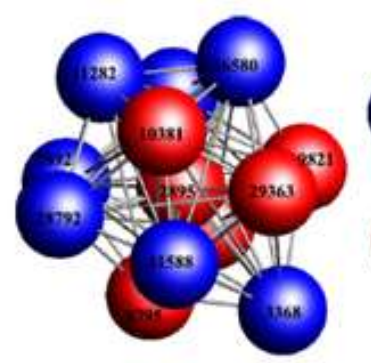

(a)

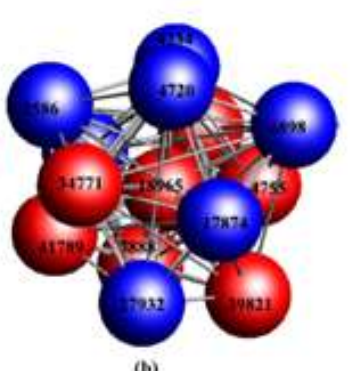

(b)

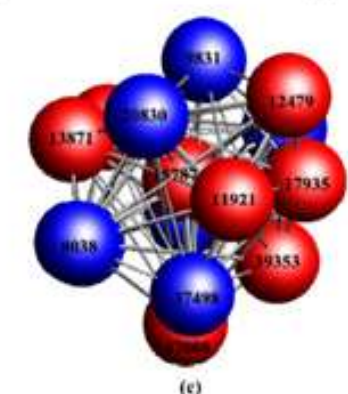

Şekil 2. Farklı türdeki polyhedron türü topakların atomik gösterimi a) (13 1110 2) kusurlu (defekte) olmuş icos türü polyhrdron b) (12 012 0) olarak nitelendirilen ideal icosadral polyhdron c) Frank-Kasper (FK) polyhedronu (14 $\left.\begin{array}{llll} & 12 & 2\end{array}\right)$ polyhedron [20]. 


\section{Bulgular ve Tartışma}

$\mathrm{Bu}$ çalışmada, $\mathrm{Pd}-\mathrm{Au}$ alaşım sistemi $\mathrm{Au}$ atomunun konsantrasyon oran1 $\mathrm{Pd}_{50} \mathrm{Au}_{50}, \mathrm{Pd}_{30} \mathrm{Au}_{70}$ ve $\mathrm{Pd}_{10} \mathrm{Au}_{90}$ olacak şekilde modellendi. Sistemleri oluşturan atomlar FCC birim hücreli $\mathrm{L}_{2}$ süper örgü noktalarına periyodik sınır koşullarına uygun olarak yerleştirildi. Sistemlerin başlangıç hızlarını belirlemek için tüm sıcaklıklarda Maxwell-Boltzman dağılımı kullanıldı. Sistemlerin hareket denklemleri Gear'ın 5. dereceden öngörücü-düzeltici algoritması kullanılarak çözüldü. Sisteme uygun potansiyel enerji parametreleri daha önceki çalışmalardan elde edildi [21]. Modellenen yapılar, 300K sıcaklıktan başlayarak 50K sıcaklık artışları ile 2000K sıcaklığına kadar her bir sıcaklık aralığında $10000 \mathrm{MD}$ adımı bekletilmek sureti ile 1sitıldı. Daha sonra model sistemin sıcaklığı sıvı fazdan itibaren düşürülerek $1 \times 10^{13} \mathrm{~K} / \mathrm{s}$ hızlı soğutma uygulanarak $300 \mathrm{~K}$ sıcaklığına düşürüldü ve sistemin amorf faza dönüşümü sağland.

Şekil 3, 300K sıcaklıkta elde edilen kristal yapıları temsil eden bazı bağlı çiftlerin sayısının $\mathrm{Au}$ atomunun konsantrasyon oranı ile değişimini göstermektedir. Genel olarak fcc örgüleri temsil eden 1421 bağlı çiftleri ile hcp örgüyü temsil eden 1422 bağlı çiftlerin sayısı Au konsantrasyonu arttıkça gözle görünür şekilde arttığı görülmektedir. Bcc kristal yapıyı temsil eden 1441 bağlı çiftlerin sayısında çok fazla bir değişim gözlenmemiştir. Bu sonuç, 300K sıcaklıkta Au atomunun eklenmesiyle hcp ve fcc sık1paket yapılarının sistemde daha fazla meydana geldiğini göstermektedir.

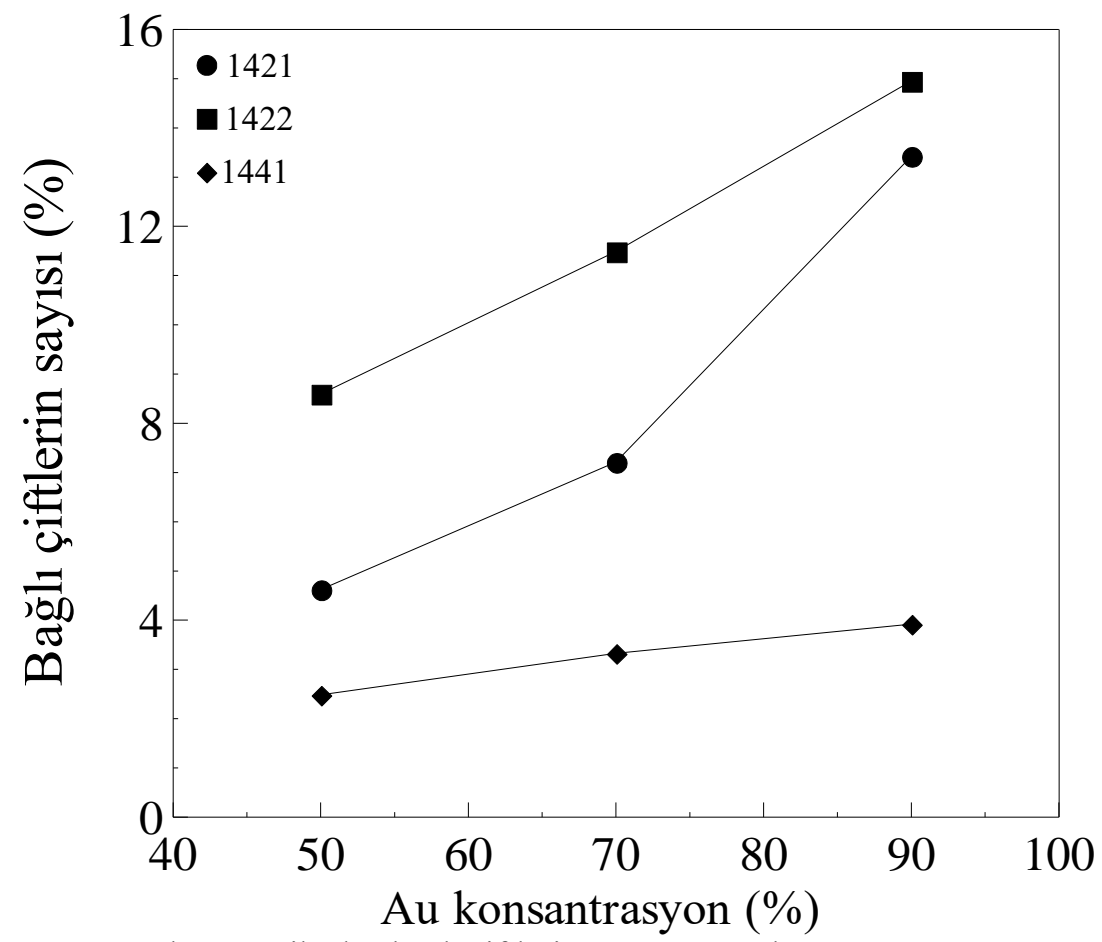

Şekil 3. Kristal yapıları temsil eden bağlı çiftlerin sayısının Au konsantrasyonuna göre değişimi

Şekil 4, 300K sıcaklıkta elde edilen ve amorf fazda görülen bazı bağlı çiftlerin sayısının (yüzdesel) Au atomunun konsantrasyon oranı ile değişimini göstermektedir. Bağlı çiftlerin sayısının değişimi incelendiğinde, Au atomunun sisteme eklenmesi ile tüm bağlı çiftlerin sayısında önemli derecede artış olduğu belirlenmiştir. İdeal icosahral (icos) yapıyı temsil eden 1551 bağlı çiftlerinin sayısının yapısal olarak kusurlu (defekte) icos yapıları temsil eden 1541 ve 1431 bağlı çiftlerin sayısından daha az olduğu görülmektedir. Bu durum hızlı soğutma sürecinde amorf fazda beklenilen bir sonuçtur. Bununla birlikte, tüm bağlı çiftlerin sayıca en fazla olduğu yapı $\operatorname{Pd}_{10} \mathrm{Au}_{90}$ da elde edilmiştir. Pd10Au90 alaşım sisteminin icos türü topakların oluşumu bakımından en uygun yapı olduğu sonucuna varılabilir. Aynı zamanda, bu tür topakların sayısının fazla olması yapının amorf fazda kararlı kaldığının bir göstergesidir.

Şekil 5, 300K sıcaklıkta elde edilen ve amorf fazda görülen bazı polyhedron topakların sayısının $\mathrm{Au}$ atomunun konsantrasyon oranı ile değişimini göstermektedir. Grafik incelendiğinde, tüm polyhedron türü topaksı yapıların $\mathrm{Au}$ konsantrasyonu arttıkça arttığı tespit edilmiştir. Yapıya $\mathrm{Au}$ 
atomunun eklenmesi ile birlikte $\left(\begin{array}{llll}12 & 0 & 12 & 0\end{array}\right)$ türü polyhedron türü topağın oluşumu daha kolay olmaktadır. Bu durum Au atomu yapısal olarak düzenli ideal icos topağının oluşumu için ideal bir atom olarak yorumlanabilir. Bununla birlikte, (10 280 ) Bernal türü polyhedronunun amorf fazda fazla diğer polyhedron türleri göre daha az meydana geldiği söylenebilir. (14 012 12 2 ) FK türü polyhedron ise amorf faz içinde oldukça fazla olmak beraber $\mathrm{Pd}_{10} \mathrm{Au}_{90}$ yapısında sayı olarak en fazla değerini almaktadır. Şekil 6 , OVITO [22] programı kullanılarak $\mathrm{Pd}_{50} \mathrm{Au}_{50}$ yapısı için $300 \mathrm{~K}$ sıcaklık ve amorf fazda elde edilen polyhedronların atomik konfigürasyonlarının resimleri gösterilmektedir. Tüm palyhedronların gösterimi zor olacağından sadece atomik koordinatları belirlenen 4 tür polyhedron türünün resmi gösterilmiştir.

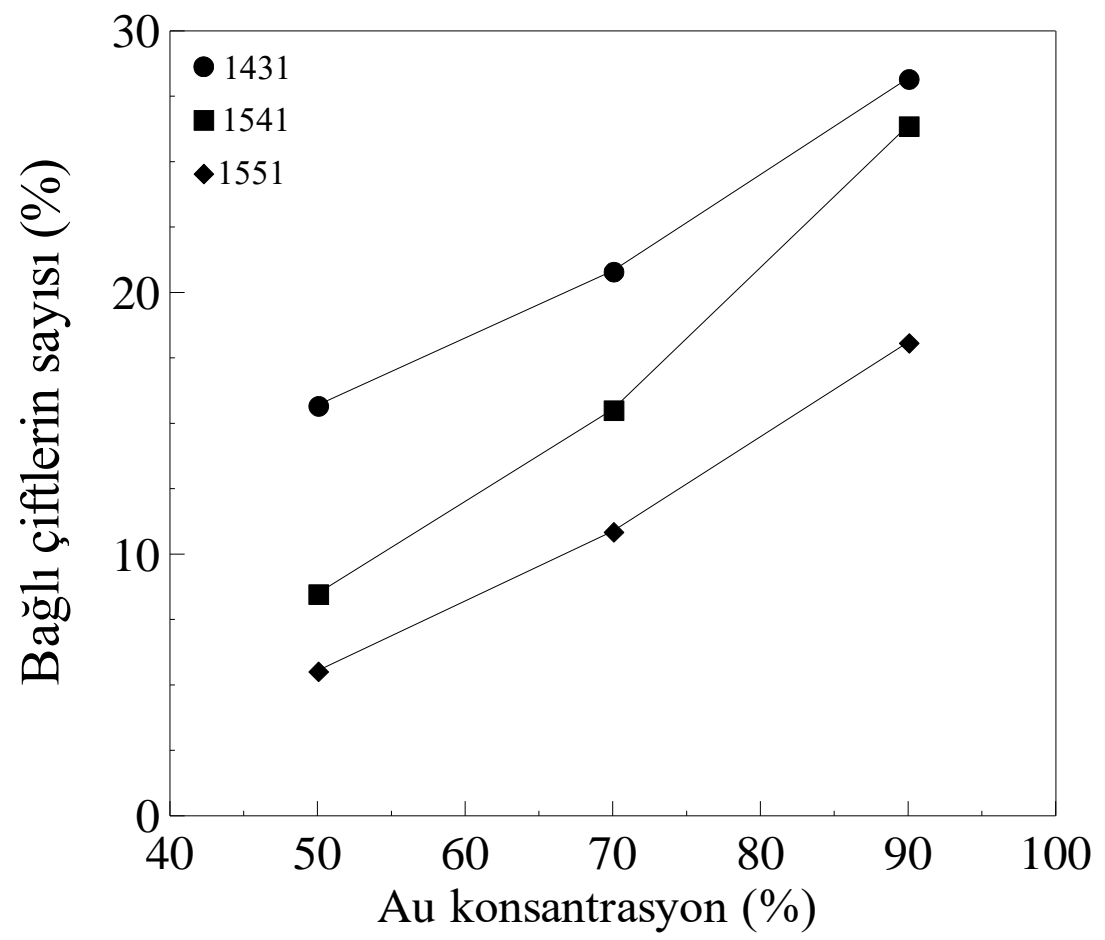

Şekil 4. Amorf fazda görülen bazı bağlı çiftlerin sayısının Au konsantrasyonuna göre değişimi

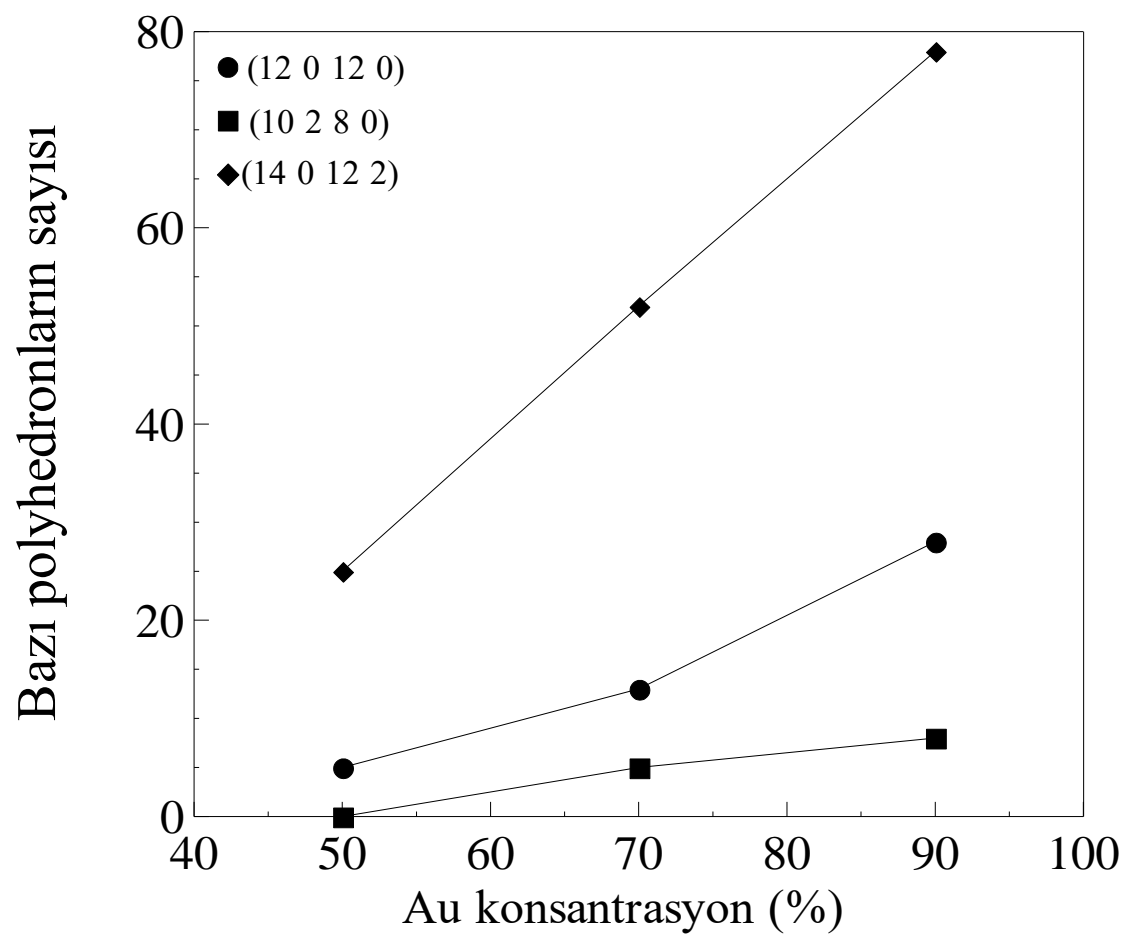

Şekil 5. Amorf fazda görülen bazı polyhedron topaklarının sayısının Au konsantrasyonuna göre değişimi 

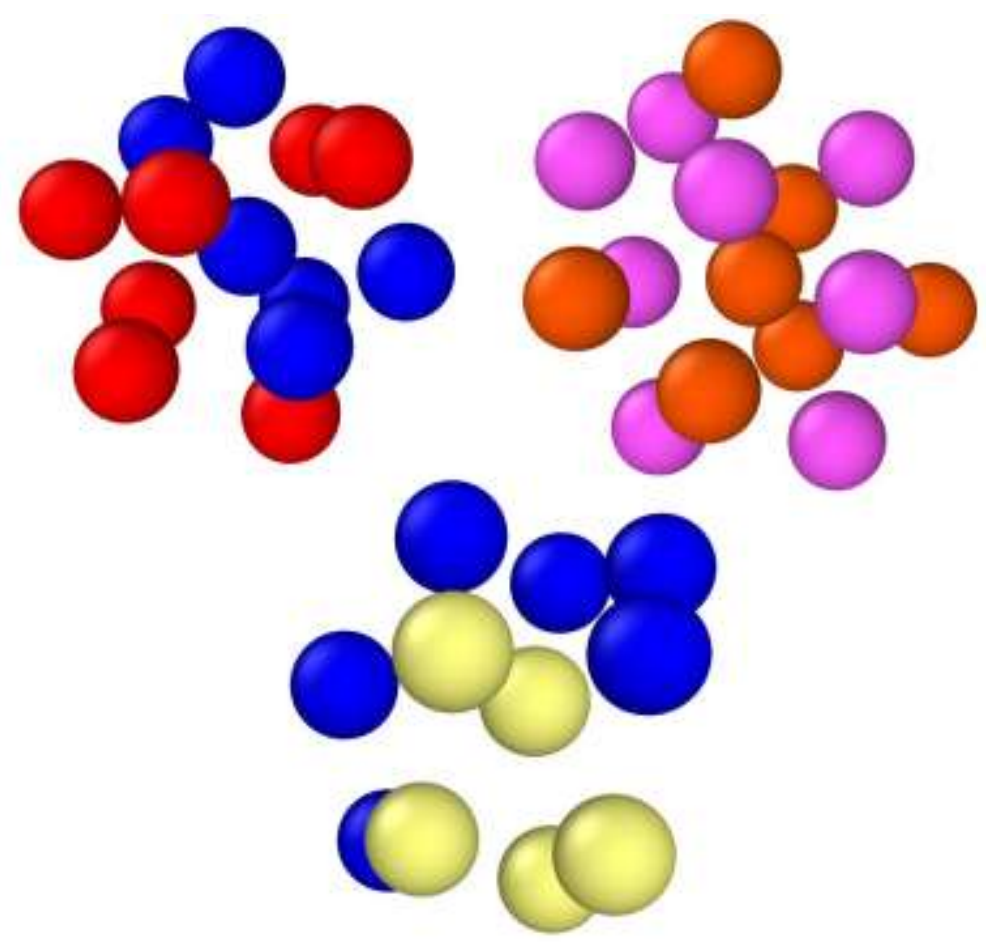

Şekil 6. 300K sıcaklıkta ve $\mathrm{Pd}_{50} \mathrm{Au}_{50}$ yapısında meydana gelen bazı polyhedron topaklarının üç boyutlu gösterimi ( 1 - mavi-kırmızı renkli (12 012 0) polyhedronu mavi Pd, kırmızı Au atomlarını temsil etmektedir, 2turuncu-pembe renkli (14 $\left.\begin{array}{llll}0 & 12 & 2\end{array}\right)$ polyhedronu pembe Pd, turuncu Au atomlarını temsil etmektedir, 3- mavi-sarı renkli (10 28 0) polyhedronu sarı Pd, mavi Au atomunu temsil etmektedir).

\section{Sonuç ve Öneriler}

$\mathrm{Bu}$ çalışmada $\mathrm{Pd}-\mathrm{Au}$ alaşımı atomlar arası etkileşimi için Sutton-Chen potansiyel enerji fonksiyonu kullanılarak MD simülasyon metodu ile modellenmiştir. $\mathrm{Au}$ atomunun konsantrasyon oranı değiştirilerek sıvı fazdan itibaren hızlı soğutularak oda sıcaklığındaki oluşan amorf fazda meydana gelen farklı türdeki polyhedron türü topaklanmalar incelenmiştir. Amorf fazda $\mathrm{Pd}_{10} \mathrm{Au}_{90}$ yapısının icos türü topakların oluşumu bakımından en uygun yapı olduğu sonucuna varılmıştır. Ayrıca, Au atomunun yapısal olarak düzenli ideal icos topağının oluşumu için ideal bir atom olduğu sonucuna varılmıştır. Bununla birlikte, (10 28 0) Bernal türü polyhedronunun amorf fazda fazla oluşmamıştır. (14 012 2) FK türü polyhedron ise faz içinde oldukça fazla olmak beraber $\mathrm{Pd}_{10} \mathrm{Au}_{90}$ yapısında sayı olarak en fazla değerini almaktadır.

\section{Yazarların Katkısı}

Makalede tüm katkı şahsıma aittir.

\section{Çıkar Çatışması Beyanı}

Yazarlar arasında herhangi bir çıkar çatışması bulunmamaktadır.

\section{Araştırma ve Yayın Etiği Beyanı}

Yapılan çalışmada araştırma ve yayın etiğine uyulmuştur.

\section{Kaynaklar}

[1] Luyten J., Schurmans M., Creemers C., Bunnik B.S., Kramer G.J. 2007. Surface segregation in $\mathrm{Pt}_{25} \mathrm{Rh}_{75}$ alloys studied by Monte Carlo simulations and the modified embedded atom method. Surface Science, 601: 1668-1676. 
[2] Garbacz H., Mizera J., Laskowski Z., Gierej M. 2011. Microstructure and mechanical properties of a Pt-Rh alloy. Powder Technology, 208: 488-490.

[3] Luyten J., De Keyzer J., Wollants P., Creemers C. 2009. Construction of modified embedded atom method potentials for the study of the bulk phase behaviour in binary Pt-Rh, Pt-Pd, Pd-Rh and ternary Pt-Pd-Rh alloys. CALPHAD: Computer Coupling of Phase Diagrams and Thermochemistry, 33: 370-376.

[4] Rdzawski Z.M., Stobrawa J.P. 2004. Microstructure and properties of the new Pt-Rh based alloys for high-temperature applications. Journal of Materials Processing Technology, 153: 681-687.

[5] Ren D.M., Qin J.H., Wang J.B., Tsong T. 1993. Oscillatory compositional depth profiles in surface segregation of a Pt-Rh alloy. Physical Review B, 47: 3944-3946.

[6] Yuge K., Seko A., Kuwabara A., Oba F., Tanaka I. 2006. First-principles study of bulk ordering and surface segregation in Pt-Rh binary alloys. Physical Review B, 74: 174202.

[7] Qi L., Dong L.F., Zhang S.L., Cui Z.Q., Ma M.Z., Jing Q, Li G., Liu R.P. 2007. Glass formation and local structure evolution in rapidly cooled Pd55Ni45 alloy melt: Molecular dynamics simulation. Comp. Mat. Sci., 42: 713-718.

[8] Zadpoor A. A. 2020. Meta-biomaterials. Biomaterials Science, 8 (1): 18-38.

[9] Lu K. 1996. Nanocrystalline metals crystallized from amorphous solids: nanocrystallization, structure, and properties. Materials Science and Engineering, R16: 161-221.

[10] Sauvage F., Schymkowitz J., Rousseau F., Schmidt B.Z., Remaut K., Braeckmans K., De Smedt S.C. 2020. Nanomaterials to avoid and destroy protein aggregates. Nano Today, 100837.

[11] Wang X., Dong S., Ashour A., Zhang W., Han B. 2020. Effect and mechanisms of nanomaterials on interface between aggregates and cement mortars. Construction and Building Materials, 240: 117942.

[12] Jian Z.Y., Chen J., Chang F.E., Zeng Z., He T., Jie W. 2010. Simulation of molecular dynamics of silver subcritical nuclei and crystal clusters during solidification. Sci China Tech Sci., 53: 32033208.

[13] Özgen S. 1997. Sayısal hesaplama yöntemlerinin şekil hatırlamalı alaşımlarda difüzyonsuz faz dönüşümlerine uygulanması. Doktora Tezi, Fırat Üniversitesi Fen Bilimleri Enstitüsü, Elazı̆̆.

[14] Parrinello M., Rahman A. 1980. Crystal structure and pair potentials: A molecular-dynamics study. Physical Review Letters, 45 (14): 1196.

[15] Daw S., Baskes M.L. 1984. Embedded-atom method: derivation and application to impuries, surfaces and other defects in metals. Physical Review B, 29: 6443-6453.

[16] Sutton A.P., Chen J. 1990. Long-range Finnis-Sinclair potentials. Philosophical Magazine Letter, 61: 139-146.

[17] Honeycutt J.D., Andersen H.C. 1987. Molecular dynamics study of melting and freezing of small Lennard-Jones clusters. Journal of Physical Chemistry, 91 (19): 4950-4963.

[18] Qi D.W., Wang S. 1991. Icosahedral order and defects in metallic liquids and glasses. Phys. Rev. B. 44: 884-889.

[19] Dong K.J., Liu R.S., Yu A.B., Zou R.P., Li J.Y. 2003. Simulation study of the evolution mechanisms of clusters in a large-scale liquid Al system during rapid cooling processes. Journal of Physics: Condensed Matter, 15 (6): 743.

[20] Celik F.A. 2014. Molecular dynamics simulation of polyhedron analysis of $\mathrm{Cu}-\mathrm{Ag}$ alloy under rapid quenching conditions. Physics Letters A, 378 (30-31): 2151-2156.

[21] Faruq M., Villesuzanne A., Shao G. 2018. Molecular-dynamics simulations of binary Pd-Si metal alloys: Glass formation, crystallisation and cluster properties. Journal of Non-Crystalline Solids, 487: $72-86$.

[22] Stukowski A. 2009. Visualization and analysis of atomistic simulation data with OVITO-the Open Visualization Tool. Model. Simul. Mater. Sci. Eng., 18: 15012. 